\section{AB0931 PERSISTENCE WITH SUBCUTANEOUSLY ADMINISTERED BIOLOGICS AMONG PATIENTS WITH PSORIATIC ARTHRITIS: ANALYSES FROM A US CLAIMS DATABASE}

K. Oelke ${ }^{1}$, O. Chambenoit ${ }^{2}$, A. Majhoo ${ }^{3}$, S. Gray ${ }^{4}$, K. Higgins ${ }^{4}$, P. Hur ${ }^{2}$.

${ }^{1}$ Rheumatic Disease Center, Glendale, Wl; ${ }^{2}$ Novartis Pharmaceuticals Corporation, East Hanover, $\mathrm{NJ} ;{ }^{3}$ Shores Rheumatology, St. Clair Shores, Ml; ${ }^{4}$ Truven Health Analytics, an IBM Company, Cambridge, MA, USA

Background: Persistence with biologic therapies among patients with psoriatic arthritis (PsA) provides insight into the real-world effectiveness of biologics in routine clinical practice. With different dosing schedules and durations of action of currently available biologics, measuring persistence using varying treatment gap cutoffs may better guide physicians in their treatment decisions.

Objectives: To evaluate the persistence of subcutaneously (SC) administered biologics in patients with PsA.

Methods: Patients with $\geq 1$ pharmacy claim for an FDA-approved SC biologic (adalimumab, certolizumab pegol, etanercept, golimumab, and secukinumab) for the treatment of PsA between 01/15/2016 and 07/31/2017 were identified in the Truven Health Analytics MarketScan Commercial and Medicare Supplemental Databases. Eligible patients were aged $\geq 18$ years at the time of biologic initiation (index date) and continuously enrolled with medical and pharmacy claims $\geq 12$ months prior to (baseline period) and $\geq 12$ months after the index date. Patients had $\geq 1$ PsA diagnosis (ICD-9-CM 696.0 or ICD-10-CM L40.5x) and no pharmacy claims for the index biologic during the baseline period. Persistence over 12 months was measured as the discontinuation rate and number of days persistent on the biologic therapy from the index date to reported treatment gaps of $\geq 45, \geq 90$, and $\geq 180$ days based on clinical expert opinion, or the end of follow-up if no gap was observed. The median time to discontinuation of the index biologic over 12 months was assessed by Kaplan-Meier analysis for each treatment gap cutoff.

Results: A total of 1558 patients with PsA enrolled in the analysis initiated SC biologics, including adalimumab $(n=720)$, certolizumab pegol $(n=93)$, etanercept $(n=426)$, golimumab $(n=64)$, and secukinumab $(n=255)$. Overall, 680 patients (43.6\%) discontinued their index biologic therapy during 12 month follow-up. The 12 month discontinuation rate for each treatment gap cutoff was lowest with secukinumab compared with other SC biologics $(51.8 \%, 36.5 \%$, and $21.6 \%$ for patients with treatment gaps $\geq 45$ days, $\geq 90$ days, and $\geq 180$ days, respectively). Mean days persistent on the index biologic was the highest with secukinumab for each treatment gap cutoff ( 254.5 days, 282.8 days, and 307.5 days for patients with treatment gaps $\geq 45$ days, $\geq 90$ days, and $\geq 180$ days, respectively) and the lowest with certolizumab pegol ( 218.1 days and 240.7 days for patients with treatment gaps $\geq 45$ days and $\geq 90$ days, respectively) and etanercept (270.7 days for patients with a treatment gap $\geq 180$ days; table 1$)$. The median $(95 \% \mathrm{Cl})$ time to discontinuation for patients with a treatment gap $\geq 45$ days was the highest with secukinumab (308 [238 to >365] days) and lowest with certolizumab pegol (216 [155 to 274] days). Median time to discontinuation could not be calculated for patients with treatment gaps $\geq 90$ days or $\geq 180$ days due to low event rates and limited follow-up.

Abstract AB0931 - Table 1. Persistence With Index Biologic Therapies Over 12 Months of Follow-Up in Patients With Psoriatic Arthritis $(\mathrm{N}=1558)$

\begin{tabular}{|l|c|c|c|c|c|}
\hline & $\begin{array}{c}\text { Adallimumab } \\
(\mathbf{n}=720)\end{array}$ & $\begin{array}{c}\text { Certolizumab } \\
\mathbf{P e g o l} \\
(\mathbf{n}=93)\end{array}$ & $\begin{array}{c}\text { Etanercept } \\
(\mathbf{n}=426)\end{array}$ & $\begin{array}{c}\text { Golimumab } \\
(\mathbf{n}=64)\end{array}$ & $\begin{array}{c}\text { Secukinumab } \\
(\mathbf{n}=\mathbf{2 5 5})\end{array}$ \\
\hline Discontlnuation of Index drug, $\mathbf{n}(\%)$ & & & & & \\
\hline Treatment gap $\geq 45$ days & $395(54.9)$ & $61(65.6)$ & $255(59.9)$ & $38(59.4)$ & $132(51.8)$ \\
\hline Treatment gap $\geq 90$ days & $307(42.6)$ & $48(51.6)$ & $203(47.7)$ & $29(45.3)$ & $93(36.5)$ \\
\hline Treatment gap $\geq 180$ days & $208(28.9)$ & $32(34.4)$ & $148(34.7)$ & $21(32.8)$ & $55(21.6)$ \\
\hline $\begin{array}{l}\text { Days persistent on index drug, mean } \\
(\text { SD) }\end{array}$ & & & & & \\
\hline Prior to gap of $\geq 45$ days & $253.2(120.5)$ & $218.1(127.1)$ & $236.5(125.8)$ & $233.5(128.4)$ & $254.5(123.8)$ \\
\hline Prior to gap of $\geq 90$ days & $266.0(123.8)$ & $240.7(131.9)$ & $249.5(130.4)$ & $253.7(132.4)$ & $282.8(117.5)$ \\
\hline Prior to gap of $\geq 180$ days & $288.7(122.7)$ & $272.1(131.8)$ & $270.7(132.5)$ & $273.0(135.7)$ & $307.5(112.2)$ \\
\hline
\end{tabular}

$<$ ??>Days persistent (ie, time to discontinuation) was defined as the time from the index prescription fill to the last day the drug was on hand to give a gap of $\geq 45,90$, or 180 days without the index drug, or the end of follow-up if no gap was observed. Conclusions: Patients who initiated secukinumab showed higher persistence over 12 months of follow-up compared with the other SC biologics assessed, regardless of the treatment gap.

Acknowledgements: This study was sponsored by Novartis Pharmaceuticals Corporation, East Hanover, NJ.

Disclosure of Interest: K. Oelke Consultant for: Novartis Pharmaceuticals Corporation, Speakers bureau: AbbVie, Amgen, Bristol-Meyers Squibb and Pfizer, O. Chambenoit Employee of: Novartis Pharmaceuticals Corporation, A. Majjhoo Grant/research support from: Novartis Pharmaceuticals Corporation, Consultant for: Novartis Pharmaceuticals Corporation, Speakers bureau: Novartis Pharmaceuticals Corporation, S. Grey Employee of: Truven Health Analytics, an IBM
Company, K. Higgins Employee of: Truven Health Analytics, an IBM Company, P Hur Employee of: Novartis Pharmaceuticals Corporation

DOI: 10.1136/annrheumdis-2018-eular.1593

\section{AB0932 HELICOBACTER PYLORI ANTIGEN SPECIFIC ANTIBODIES IN PSORIATIC ARTHRITIS}

E. Patrikiou ${ }^{1}$, C. Liaskos ${ }^{1}$, E. Zafiriou ${ }^{2}$, G. Efthymiou ${ }^{1}$, T. Scheper ${ }^{3}$, W. Meyer ${ }^{3}$, A. Roussaki-Schulze ${ }^{2}$, L.I. Sakkas ${ }^{1,1}$, D.P. Bogdanos ${ }^{1} .{ }^{1}$ Rheumatology and Clinical Immunology, ${ }^{2}$ Dermatology, Faculty of Medicine, School of Health Sciences, University of Thessaly, Larissa, Greece; ${ }^{3}$ Institute of Immunology, EUROIMMUN, Lübeck, Germany

Background: The role of Helicobacter pylori $(\mathrm{Hp})$ infection in the aetiopathogenesis of psoriatic arthritis (PsA) and psoriasis (Ps) is currently inconclusive, as studies reported increased, decreased or comparable to controls frequency of anti-Hp antibodies.

Objectives: To test antigen-specific $\mathrm{Hp}$ antibodies in a well-defined cohort of PsA patients and demographically matched Ps patients and healthy controls (HCs). Methods: A total of 140 serum samples (48 PsA, 37 Ps and $55 \mathrm{HCs}$ ) were tested for anti-Hp antibodies by a western blot immunoassay using whole $\mathrm{Hp}$ extract as antigenic source.

Results: Overall, anti-Hp seropositivity was similar in PsA (19/48, 39.6\%) and Ps $(16 / 3743.2 \%, p>0.05)$ but significantly lower compared to HCs $(33 / 55,60 \%$, PsA vs $\mathrm{HC}, \mathrm{p}=0.039)$. Overall, $\lg \mathrm{G}$ anti-CagA and $\mathrm{VacA}$, the most diagnostically relevant anti-Hp antibodies, were present in $26 / 48(54.2 \%)$ and $5 / 48(10.4 \% \%)$ PsA patients, respectively, compared to $15 / 37(40.5 \%)(p=n s)$ and $1 / 37(2.7 \%)(p=n s)$ Ps respectively, as well as in 39/55 (70.9\%), ( $p=0.079)$ and 4/55/97.2\%) ( $p=n s)$ $\mathrm{HCs}$, respectively. Compared to $\mathrm{HCs}$, patients with $\mathrm{PsA}$ had higher reactivity to p29 (UreA) $(31 / 48,64.6 \%$ vs $24 / 55,43.5 \%, p=0.033)$ and to p54 $(24 / 48,50 \%$ vs $15 / 55,27.2 \%, p=0.017$ ) and tended to have higher positivity against p75 antigen $(9 / 48,18.9 \%$ vs $3 / 55,5.4 \%, p=0.062)$. Reactivity to $p 50(15 / 48,31.3 \%$ vs 50.9 , $p=0.042)$ and $p 33$ antigen $(3 / 48,6.3 \%$ vs $10 / 55,18.2 \%, p=0.061)$ was lower in PsA than in HCs. No differences on anti-Hp antigen specific antibodies was found between PsA and Ps

Conclusions: Although overall reactivity to $\mathrm{Hp}$ in $\mathrm{PsA}$ and $\mathrm{Ps}$ is lower than $\mathrm{HCs}$, $\mathrm{Hp}$ infection cannot safely be considered a protecting microbial agent for these diseases, as reactivities to some $\mathrm{Hp}$ antigens are more frequently recognised to these diseases than in $\mathrm{HCs}$.

Disclosure of Interest: E. Patrikiou: None declared, C. Liaskos: None declared, E. Zafiriou: None declared, G. Efthymiou: None declared, T. Scheper Employee of: EUROIMMUN, W. Meyer Employee of: EUROIMMUN, A. Roussaki-Schulze: None declared, L. Sakkas: None declared, D. Bogdanos: None declared DOI: 10.1136/annrheumdis-2018-eular.6716

\section{AB0933 SURVIVAL AT 6 AND 12 MONTHS OF USTEKINUMAB IN PATIENTS WITH PSORIATIC ARTHRITIS IN CONDITIONS OF CLINICAL PRACTICE}

L. Perez Albaladejo, I. Notario Ferreira, I. Añón Oñate, M. Á. Ferrer González, M. J. Soto Pino, S. Quirosa Flores, A. García Sánchez, M.C. Ramírez Barberena, M. Ramírez de la Torre, J.M. Andreu Ubero, R. Cáliz Cáliz. HOSPITAL UNIVERSITARIO VIRGEN DE LAS NIEVES, Granada, Spain

Introduction: Psoriatic arthritis (PsA) is a chronic inflammatory disease associated with skin psoriasis. Ustekinumab is a monoclonal antibody which inhibits IL12/23 and has proven efficacy and safety in the treatment of patients with PsA.

Objectives: To determine the survival rate and the reasons for Ustekinumab discontinuation in a patient cohort with PsA in conditions of clinical practice.

Methods: Descriptive, prospective, longitudinal and open study including 66 patients diagnosed with PsA and treated with Ustekinumab at dosis according to the data sheet (45 mg in the 0,4 and every 12 weeks), except for 3 patients who were administered a $90 \mathrm{mg}$ dose with the aforementioned regimen. The patients were monitored at 6 and 12 months. The following variables were collected: age, sex, years of evolution, previous treatment with Synthetic Disease Modifying AntiRheumatic Drugs (DMARDs) and/or biologic DMARD. All the adverse events $(A E)$ which caused the discontinuation of the drug in patients who had received at least one dose of Ustekinumab were also collected. The Kaplan-Meier method was used to analyse the survival rate. The survival rate in naïve patients with biologic DMARD was compared with those who had received at least one biologic DMARD treatment before; and patients treated with Ustekinumab in monotherapy with those who were in a combined therapy with DMARDs. The Log-Rank Test was used for the comparative analysis of both subgroups

Results: Out of the 66 patients of our cohort, 34 (51.5\%) were women, whose mean age was $47.2 \pm 11.3$ years. 49 presented only peripheral affectation $(74.2 \%)$ mainly in polyarticular form, and 10 had mixed affectation. The rest presented axial affectation exclusively. Our patients had been suffering from this disease for 